\section{AGRICULTURE AND WORLD NUTRITIONAL NEEDS}

$\mathrm{P}_{\mathrm{t}}^{\mathrm{R}}$ ROF. J. R. MARRACK delivered on April 16 the third of a series of lectures arranged by the Harpenden Branch of the Association of Scientific Workers on "Agriculture and World Nutritional Needs". On the subject of "Food, Relief and Reconstruction", Prof. Marrack said that at the best, supply of food in the continent of Europe when fighting ceases will be as low as in November 1918. It is quite probable that the Nazis will spoil and lay waste large areas and leave the population completely destitute. The provision of adequate relief will be limited by two factors, namely, transport and supplies. The transport problem will be particularly acute, when a considerable area of Europe has been freed and fighting still continues, as transport will still be supplying the Army. When fighting has ended in Europe shipping will still be needed to carry supplies on the long voyage to the Far East. The problem of supplies will become most acute when the whole of Europe is freed. Nearly 500 million people will need to be provided with at least one third of their calories. It may be possible to accumulate stocks to meet this need; but they will be even shorter of animal foods than of total calories, and there is little prospect that stocks of suitable foods will have been accumulated. Pork products, large amounts of which will be available, are mainly fat and do not meet the need for protein.

Vitamin deficiencies will not be equally distributed. There should be sufficient supplies of concentrated preparations (with the exception of riboflavin) for treating the more severe manifestations of vitamin deficiency, but not for indiscriminate broadcast.

It is obvious that during this period of extreme shortage, which will last up to the next harvest, production, transport and distribution of food must be controlled and rationing. of individual consumption may be more severe than it is now. But the shortage, particularly of animal foods, will continue for some years, and if we set out to abolish the fear of want we must aim at changing the character of the world's food supply. On the average, it provides enough, or nearly enough, calories; the fault is lack of animal foods, fruit and vegetables. Until a change in the type of food produced has taken place, it will be essential to maintain the supply of calories, at least. Otherwise peasants will continue to wring the maximum number of calories from the soil by cereal culture. The change in diet aimed at is qualitative. But the change in food production is, in the end, quantitative, since animals are poor converters and it takes ten or more calories of feeding stuffs to produce one calorie of human food.

For the immediate future we must accept the distribution of the world's population, with densely populated and sparsely populated areas. Production should be planned to ensure that the densely populated areas produce the perishable animal and vegetable foods for their own consumption and import the portable cereals from the sparsely populated areas. To ensure that the food is produced as needed and that those who need it can buy it, it will be necessary to have a Supreme Economic Council that will control production and distribution and will adjust purchasing power to requirements.

\section{LOCUSTS AND OTHER MIGRATORY INSECTS IN INDIA}

TN a land of continental features like India there are major insect pests which have the capacity of spreading from one part of the country to another. Where such pests appear more or less regularly and are of relatively confined distribution the provincial entomologists should be well fitted to study them and devise control measures. In the case of the desert locust, for example, swarms may appear in the Punjab, the United Provinces and Rajputana, and are known to have been derived from outbreak areas in Baluchistan, Iran and Arabia. Similarly, locusts from Rajputana and the Punjab may migrate as far afield as Assam and Madras. It will be clear that, in such cases, the provincial entomologist would be severely handicapped if he had to attempt the control of an insect the origin of which was in a distant province of India.

This subject is fully discussed by Rao Bahadur Y. Ramchandra Rao in his presidential address to the Section on Agricultural Sciences at the thirtieth Indian Science Congress in Calcutta, 1943. It is pointed out in this discourse that an All-India agency is necessary for dealing with pests of this kind, and one of its functions would be to circulate timely warning to those provinces likely to be affected. For the past three years such an agency has been function. ing in so far as the desert locust is concerned. The Bombay locust and the migratory locust are of sufficient importancè to merit similar centralized methods of attack.

There are also several migratory species of Lepidoptera the larvæ of which entail great damage. Thus the paddy armyworm (Spodoptera maurita) appears in huge numbers on young paddy, especially in Malabar, causing enormous damage. It appears so suddenly and disappears so speedily from the scene of its activities that there is scarcely any time for taking remedial measures. In many cases there are definite indications that such infestations had come into existence by the appearance of flights of the parent moths from some distant land, followed by prolific deposition of eggs on the paddy crop. On issuing from the pupx the resulting moths would appear to have flown to some other area.

In Bihar, the cutworm, Agrotis ypsilon, appears in numbers on autumn crops, but is not to be found in the plains between April and August. It is surmised that it migrates to the hills during spring and summer and returns to the plains in the autumn. Similarly, the cabbage white butterfly (Pieris brassica) breeds on the plains of northern India only in winter and spring, disappearing during April and apparently migrating to the hills for summer breeding.

Examples of this kind where pests are capable of spreading from one province to another require investigation by some central agency that can have access to all affected areas. Mr. Ramchandra Rao discusses the Bombay locust (Patanga succincta) in detail and points out that very little is known regarding its habits and phases. The real need at present, he stresses, would appear to be for a system of planning out research on an all-India basis of those problems that cannot obviously be attacked by a provincial agency. In the course of the last two decades various committees have been constituted on such a basis for research on various crops, including some of their insect pests. In this manner a consider- 